\title{
The Use of Disposable Laryngeal Mask Airway for Adenotonsillectomies
}

\author{
Dante Ranieri Junior, TSA ${ }^{1}$, Adecir Geraldo Neubauer, TSA 2, Denise Marchi Ranieri ${ }^{3}$, \\ Paulo do Nascimento Junior, TSA 4
}

Summary: Ranieri Jr D, Neubauer AG, Ranieri DM, Nascimento Jr P - The Use of Disposable Laryngeal Mask Airway for Adenotonsillectomies.

Background and objectives: Tracheal intubation associated with airway operations can cause complications such as laryngospasm, bronchospasm and periods of reduced oxygen saturation. Such complications are frequently reported during adenotonsillectomies, a procedure that by nature increases the incidence of airway complications. The objective of this study was to compare the occurrence of respiratory problems during adenotonsillectomies while using either a disposable laryngeal mask airway (LMA) or an endotracheal tube (TT).

Methods: We evaluated 204 pediatric patients undergoing general anesthesia for adenotonsillectomies. The patients were randomly allocated into either the tracheal intubation group $(T T, n=100)$ or the laryngeal mask airway group $(L M A, n=104)$. It was measured the level of oxygen saturation by pulse oximetry $\left(\mathrm{SpO}_{2}\right)$ after the induction of anesthesia $\left(\mathrm{SpO}_{2}-1\right)$, after establishing the operative field $\left(\mathrm{SpO} \mathrm{S}_{2}-2\right)$, at the end of the surgical procedure $\left(\mathrm{SpO}_{2}-3\right)$, three minutes after the removal of the contained breathing apparatus $\left(\mathrm{SpO}_{2}-4\right)$ and upon admission to the post-anesthesia care unit $\left(\mathrm{SpO}_{2}-5\right)$. All respiratory complications were recorded.

Results: The mean $\mathrm{SpO}_{2}$ values and standard deviations for the TT and LMA groups were as follows: $\mathrm{SpO}_{2}-1: 98.9 \pm 1.0$ and $98.7 \pm 0.8$ ( $p>0.25$ ), $\mathrm{SpO}_{2}-2: 97.4 \pm 1.0$ and $94.9 \pm 4.3(p<0.001), \mathrm{SpO}_{2}-3: 96.9 \pm 1.1$ and $97.2 \pm 1.1(p=0.037), \mathrm{SpO}_{2}-4: 91.7 \pm 9.0$ and $95.2 \pm 2.2(p<0.001)$ and $\mathrm{SpO}_{2}-5: 94.0 \pm 2.1$ and $95.8 \pm 2.6(p<0.001)$, respectively. In the LMA group, 12 patients required some maneuvering to fix positioning and leaks during surgery. In four patients, the LMA had to be replaced with a TT. Respiratory complications were similar between groups.

Conclusions: Performing adenotonsillectomies in pediatric patients using a $\mathrm{LMA}$ resulted in a lower intraoperative $\mathrm{SpO}_{2}$, compared to using a TT. In some cases, the LMA had to be replaced with an endotracheal tube. Although the surgery may be performed with LMA, the use of a TT is preferred for safety.

Keywords: Bronchial spasm; Intubation, Intratracheal; Laryngeal Masks; Laryngismus; Otolaryngology/surgery; Respiratory Aspiration.

Financial support: The study was solely funded by the anesthesiology service.

C2012 Elsevier Editora Ltda. All rights reserved.

\section{INTRODUCTION}

Respiratory complications such as bronchospasm, laryngospasm and hypoxemia are common in pediatric anesthesia, especially during adenotonsillectomies, because of the patients' Received from the Department of Anesthesiology and Otorhinolaryngology, Hospital do
Coração de Balneário Camboriú, Santa Catarina, Brazil.

1. Anesthesiologist; Intensivist, PhD student at Department of Anesthesiology, Faculdade de Medicina de Botucatu, Universidade Estadual de São Paulo (FMB, UNESP) and co-head of the Training and Teaching Center (SBA-CET), IPA, Itajaí, SC, Brazil

2. Anesthesiologist; Instructor of the SBA-CET IPA, Itajaí, SC, Brazil

3. ENT, Master ENT and Head and Neck Surgery Escola Paulista de Medicina, Universidade

Federal de São Paulo (UNIFESP), Professor of Universidade do Vale do Itajaí (Univali), Itajaí, SC, Brazil

4. PhD; Anesthesiologist; Intensivist, Associate Professor, Department of Anesthesiology, Faculdade de Medicina de Botucatu, Universidade Estadual de São Paulo (FMB, UNESP), Brazil

Submitted on November 23, 2011.

Approved on January 23, 2012

Correspondence to:

Dante Ranieri Junior, $M D$

Rua XV de Novembro, 222 p. 10

Centro

88301420 - Itajaí, SC, Brazil

E-mail:deranieri@terra.com.br small airways, hyperreactivity to infectious and inflammatory processes and the presence of secretions and blood. Thus, adenotonsillectomies continue to be challenging for anesthesiologists.

Laryngospasm is among the most feared respiratory complications, occurring in 0.1 to $27 \%$ of cases, causing severe hypoxemia and requiring immediate treatment. The factors that increase the risk of laryngospasm include: small children, endotracheal intubation, inhalation anesthesia, inadequate anesthesia depth, respiratory infections and the presence of secretions in the pharynx. Treatment consists of increasing the pressure in the airway with a face mask, which can cause regurgitation, and administering succinylcholine, a drug that can trigger allergic reactions, cardiac arrhythmias, rhabdomyolysis and malignant hyperthermia ${ }^{2,3}$.

In an attempt to reduce the risks associated with this procedure, Williams et al. ${ }^{3}$ used a reinforced laryngeal mask airway during anesthesia for otorhinolaryngology and reported a reduced incidence of laryngospasm, cough and hypoxemia ${ }^{3}$.

The use of supraglottic devices in head and neck surgery remains controversial, primarily due to increased confidence among anesthesiologists in using conventional endotracheal intubation techniques, thereby protecting the airway. However, 
some authors have suggested that there is a lower complication rate with laryngeal mask airways 4,5 .

We therefore hypothesized that a laryngeal mask airway would decrease the incidence of respiratory complications compared to endotracheal intubation during adenotonsillectomies.

The aim of this study was to compare conventional endotracheal intubation to a Unique ${ }^{\circledR}$ disposable laryngeal mask airway by evaluating the levels of blood oxygenation and the occurrence of respiratory complications during adenotonsillectomies.

\section{METHODS}

This study was approved by the Institutional Ethics Committee and registered at Australian and New Zealand Clinical Trials (ANZCT No. 12611001101976). The patient's parent or legal guardian signed informed consent forms prior to surgery. Adenotonsillectomy patients, with an ASA I physical status and between 2 and 10 years of age, were included in the study.

Our exclusion criteria were respiratory tract infections in the last two weeks, purulent secretions from the tonsils, gastroesophageal reflux and coagulation disorders assessed by a coagulogram. The same anesthesia-surgical team performed all operations, and all members were experienced with both the proposed surgery and pediatric anesthesia.

Thirty minutes prior to admission to the operating room, all patients received oral midazolam as pre-anesthetic medication at a dose of $0.3 \mathrm{mg} \cdot \mathrm{kg}^{-1}$, with a maximum water volume of $5 \mathrm{~mL}$. Monitoring consisted of an electrocardiogram in DII (ECG), pulse oximetry $\left(\mathrm{SpO}_{2}\right)$, non-invasive blood pressure and capnography (Dash 4000, GE Healthcare, Fairfield). Anesthesia was induced with inhaled $3 \%$ sevoflurane in oxygen and $50 \%$ nitrous oxide. After the loss of corneal reflexes, a 22 or $24 \mathrm{G}$ Teflon intravenous catheter was inserted, and $2.0 \mu \mathrm{g} . \mathrm{kg}^{-1}$ of fentanyl and $1.0 \mathrm{mg} \cdot \mathrm{kg}^{-1}$ of propofol were injected.

Using sealed security envelopes, patients were randomly allocated into the disposable laryngeal mask airway group (Unique $\AA$ - LMA Company, London) (LMA group) or the cuffed tracheal tube group (Rush, Jaffrey) (TT group). The size of the laryngeal mask airway was determined according to the manufacturer's specifications. Children weighing between 10 and $20 \mathrm{~kg}$ received a $\mathrm{N}^{\circ}$. 2.0 laryngeal mask airway, children weighing between 20 and $30 \mathrm{~kg}$ received a No. 2.5 laryngeal mask airway, and children weighing more than $30 \mathrm{~kg}$ received a $N^{\circ}$. 3.0 laryngeal mask airway.

After patients were placed in an extended neck position, with their heads below their chest level (Rose position), gauze was anchored to the esophageal introitus in the TT group. Ventilation was maintained with a Mapleson D system, which consisted of spontaneous or manually assisted breathing, with a non-valve system without an absorber. All patients received dipyrone $\left(20 \mathrm{mg}^{\mathrm{kg}}{ }^{-1}\right)$ and dimenhydrinate $\left(200 \mu \mathrm{g} \cdot \mathrm{kg}^{-1}\right)$ intravenously.

Mclvor mouth gags were used in all patients, and the laryngeal mask airway or tracheal tube was inserted through the gag.
After the surgery was complete and homeostasis was confirmed, though prior to suturing and applying bismuth subgallate, the patients were placed in a horizontal supine position. A tracheoscopy was performed with a $4.5 \mathrm{~mm}$ flexible fiberscope (Pentax, Osaka) for laryngeal mask airways № 2.5 and 3.0 and tracheal tubes over $5.0 \mathrm{~mm}$ in diameter. For smaller devices, a $3 \mathrm{~mm}$ device was used (Smith and Nephew, Solothrun).

To remove the devices in both groups, the patients were positioned in a lateral decubitus position, and the laryngeal mask airway or tracheal tube was removed after the patient displayed spontaneous eye opening and active limb movement. The patients were then ventilated with $100 \% \mathrm{O}_{2}$ using a face mask at a flow rate of 5 L. min $^{-1}$. After patients demonstrated a regular breathing pattern, they were sent to the postanesthesia care unit (PACU) where they continued to receive oxygen via face mask at a flow rate of 5 L. $\mathrm{min}^{-1}$. The patients could leave the PACU after maintaining an oxygen saturation, measured by pulse oximetry, above $92 \%$ on room air. Patients were discharged 6 hours after the procedure.

The studied data were the lowest hemoglobin saturation value measured by pulse oximetry $\left(\mathrm{SpO}_{2}\right)$ in the following times: after the induction of anesthesia $\left(\mathrm{SpO}_{2}-1\right)$, after the establishment of the operative field $\left(\mathrm{SpO}_{2}-2\right)$, at the end of the surgical procedure $\left(\mathrm{SpO}_{2}-3\right)$, three minutes after the removal of the contained breathing apparatus $\left(\mathrm{SpO}_{2}-4\right)$ and upon admission to the post-anesthesia care unit $\left(\mathrm{SpO}_{2}-5\right)$.

There could be seen the occurrence of respiratory complications according to the following definitions:

Bronchospasm: expiratory difficulty, use of accessory muscles, decreased oxygen saturation, wheezing, snoring and pulmonary secretions. Treatment: $100 \%$ oxygen, nebulized ipratropium bromide, fenoterol and $5 \mathrm{mg} \cdot \mathrm{kg}^{-1}$ of hydrocortisone administered intravenously.

Laryngospasm: paradoxical breathing without actual ventilation, rapid reduction in $\mathrm{SpO}_{2}$. Treatment: $100 \%$ oxygen, airway pressurization, $0.04 \mathrm{mg} \cdot \mathrm{kg}^{-1}$ of atropine and $1.0 \mathrm{mg} \cdot \mathrm{kg}^{-1}$ of succinylcholine.

Stridor: use of accessory muscles, retraction of the sternal furcula, tachypnea. Treatment: 100\% oxygen, nebulization with oxymetazoline and positioning the patient supine with a $30^{\circ}$ tilt.

Wheezing: frequency and amplitude of respiratory movements is increased while maintaining an appropriate $\mathrm{SpO}_{2}$. Treatment: lateral supine position, nebulization with humidified oxygen using a facemask.

We also checked for the presence of blood in the trachea during tracheoscopy.

\section{Statistics}

The number of participants needed for the study was determined according to the proportions described by El-alami et al. ${ }^{2}$, who reported that the incidence of laryngospasm dur- 
ing adenotonsillectomy could reach $27 \%$, and Nascimento et al. ${ }^{5}$, who reported that respiratory complications occurred in $43 \%$ of children showing any pre-operative symptoms related to airway disease. Assuming an average value for this incidence and defining the errors of the hypothesis as $\beta=0.8$ and $\alpha=0.05$, we established the minimum number of participants to be 180 and divided them into 2 groups for the study. It was used Student's t-test for the continuous quantitative variables and a chi-squared test for the categorical variables. We defined a $p$-value of $<0.05$ as being statistically significant. The data were analyzed using the STATISTICA software (data analysis software system, version 6, 2001; StatSoft, Inc., Tulsa).

\section{RESULTS}

Subject to the exclusion criteria, we invited 220 patients to participate in the study, and 16 invited participants were excluded. Ten refused to sign the informed consent form, and six refused pre-anesthesia medication or preferred intravenous induction (Figure 1).

There were 100 patients in the TT group and 104 in the LMA group. There was no statistically significant difference between the groups with respect to demographic data or the length of the operation (Table I). Hemoglobin saturation values measured by pulse oximetry are presented in Table II.

The laryngeal mask airway was not fixed with tape, which allowed the surgeon to move it if necessary. This allowed the surgeon to best visualize the surgical field.

In three LMA group patients (2.8\%), we were only able to position the laryngeal mask airway with the aid of a laryngoscope because the tonsils were very hypertrophic. In eight LMA group patients $(7.7 \%)$, there was a gas leak when positioning for surgery. We noticed that cervical hyperextension caused anterior displacement of the laryngeal mask airway. In five of these patients, repositioning the laryngeal mask airway was sufficient to contain the leak. However, in three patients, it was necessary to exchange the laryngeal mask airway for an endotracheal tube. One patient in the LMA group regurgitated
Table I - Demographic Data (Age, Weight, Gender) and Surgical Time in Groups Tracheal Tube (TT) and Laryngeal Mask (LM)

\begin{tabular}{lll}
\hline & Group TT $(\mathbf{n}=\mathbf{1 0 0})$ & Group LM $(\mathbf{n}=\mathbf{1 0 4})$ \\
\hline Age (years) & $6.0 \pm 2.5$ & $5.4 \pm 2.3$ \\
Weight $(\mathrm{kg})$ & $22.1 \pm 6.7$ & $20.8 \pm 6.3$ \\
Gender (M/F) & $44 / 56$ & $52 / 48$ \\
$\begin{array}{l}\text { Surgical time } \\
\text { (minutes) }\end{array}$ & $16.0 \pm 2.3$ & $19.4 \pm 2.0$ \\
\hline
\end{tabular}

$p>0,05$. Numbers show as mean and standard deviation (age, weight and surgical time) and absolute values (gender).

Table II - Hemoglobin Pulse Saturation Values $\left(\mathrm{SpO}_{2}\right)$ in Tracheal Tube (TT) and Laryngeal Mask (LM) Groups

\begin{tabular}{llll}
\hline & $\begin{array}{l}\text { Group TT } \\
(\mathrm{n}=100)\end{array}$ & $\begin{array}{l}\text { Group LM } \\
(\mathrm{n}=104)\end{array}$ & Statistics \\
\hline $\mathrm{SpO}_{2}-1$ & $98.6 \pm 1.0$ & $98.7 \pm 0.8$ & $\mathrm{p}=0.25$ \\
$\mathrm{SpO}_{2}-2$ & $97.4 \pm 1.0$ & $94.9 \pm 4.3$ & $\mathrm{p}<0.001$ \\
$\mathrm{SpO}_{2}-3$ & $96.9 \pm 1.1$ & $97.2 \pm 1.1$ & $\mathrm{p}=0.037$ \\
$\mathrm{SpO}_{2}-4$ & $91.7 \pm 9.0$ & $95.2 \pm 2.2$ & $\mathrm{p}<0.001$ \\
$\mathrm{SpO}_{2}-5$ & $94.0 \pm 2.1$ & $95.8 \pm 2.6$ & $\mathrm{p}<0.001$ \\
\hline
\end{tabular}

Moments: after anesthesia induction $\left(\mathrm{SpO}_{2}-1\right)$; after the surgical field was established $\left(\mathrm{SpO}_{2}-2\right)$; when surgery ended $\left(\mathrm{SpO}_{2}-3\right)$; three minutes after the respiratory device was taken off $\left(\mathrm{SpO}_{2}-4\right)$ at post-anesthesia care unit admission $\left(\mathrm{SpO}_{2}-5\right)$. Data represented as mean and standard deviation.

gastric content. This phenomenon was readily identified by the surgeon before any clinical signs or change in the monitor settings were evident. The surgery was interrupted, the oropharynx aspirated while oxygen saturation fell to $58 \%$. A tracheal intubation was performed and $\mathrm{SpO}_{2}$ levels remained above $98 \%$, with an $\mathrm{FiO}_{2}$ above 0.5 . The patient developed wheezing during post-anesthesia recovery but maintained

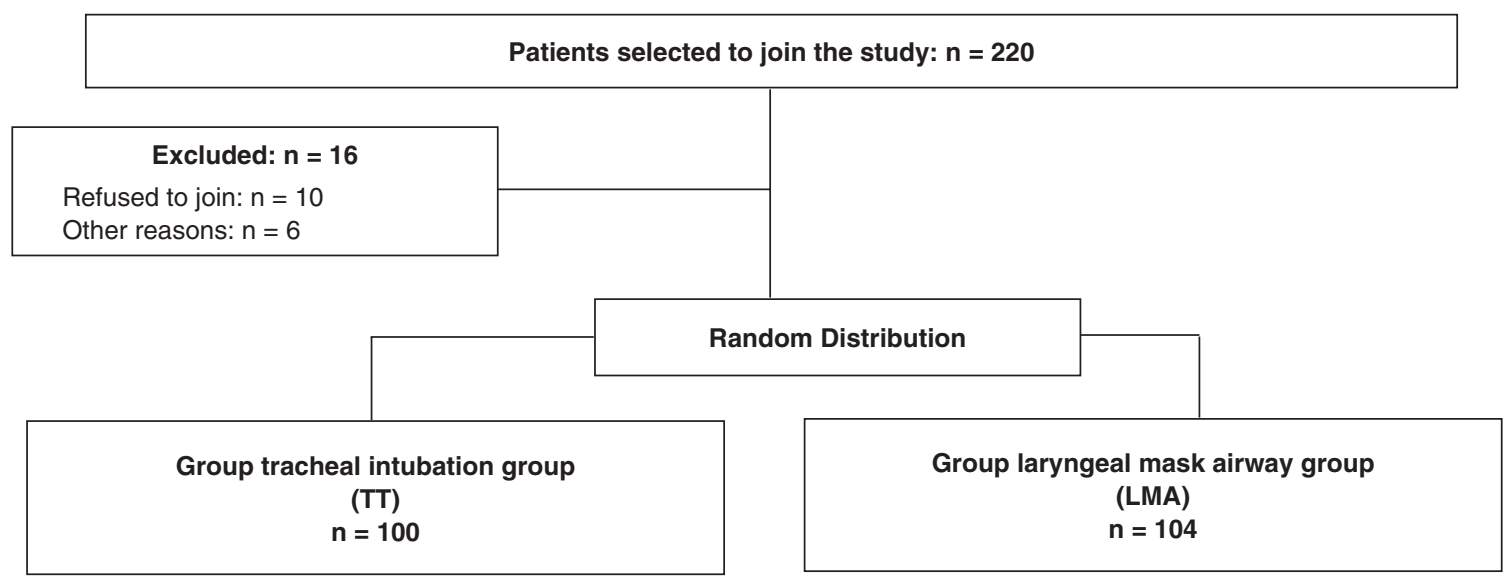

Figure 1 Patients Flow. 
an oxygen saturation above 92\%. Pulmonary auscultation revealed crackles but chest radiograph was normal, though. The patient was discharged from the hospital the same day.

There were no significant differences when comparing respiratory complications between the two groups (Table III).

Table III - Respiratory Complications at Tracheal Tube (TT) and Laryngeal Mask (LM) Groups

\begin{tabular}{llll}
\hline & $\begin{array}{l}\text { Group TT } \\
(\mathrm{n}=100)\end{array}$ & $\begin{array}{l}\text { Group LM } \\
(\mathrm{n}=104)\end{array}$ & Statistics \\
\hline Broncospasm & $8(8 \%)$ & $5(4.9 \%)$ & $\mathrm{p}=0.518$ \\
Laringospasm & $4(4 \%)$ & $1(0.9 \%)$ & $\mathrm{p}=0.342$ \\
Stridor & $7(7 \%)$ & $2(1.9 \%)$ & $\mathrm{p}=0.154$ \\
Breathing Noise & $8(8 \%)$ & $10(9.6 \%)$ & $\mathrm{p}=0.873$ \\
Regurgitagion & $0(0 \%)$ & $1(0.9 \%)$ & $\mathrm{p}=0.984$ \\
\hline
\end{tabular}

Data in frequency and percent rate.

The occluder (cuff) of the laryngeal mask airway was visible in all patients without making surgical access more difficult (Figure 2).

During the flexible tracheoscopy at the end of surgical procedure, three patients (3\%) in the TT group and seven patients $(6.7 \%)$ in the LMA group had blood in their trachea $(p>0.05)$. However, none of these patients had respiratory complications.

\section{DISCUSSION}

In this study, we found that after positioning the mouth opener, patients in the LMA group had lower $\mathrm{SpO}_{2}$ values compared to patients in the TT group. This finding was because of an



Figure 2 Patient without the Occluder (Cuff) of the Laryngeal Mask Airway. air leak that required repositioning of the mouth opener and laryngeal mask airway until both were in an acceptable position. The leaks often occurred after the neck was extended because of the antero-superior movement of the laryngeal mask airway. Exchanging the tongue retractor and the mouth opener for a larger size may help solve this problem in the future ${ }^{6}$.

In an attempt to prevent an unplanned tracheal intubation, we exchanged the laryngeal mask airway for a tracheal tube in three patients because repositioning the laryngeal mask airway was not sufficient to seal the larynx. Without a sufficient seal, the patient would be at an increased risk of serious complications such as hypoxemia, aspiration and trauma. We found that $8 \%$ to $11.4 \%$ of adenotonsillectomy cases initially performed with a laryngeal mask airway required replacement with an endotracheal tube.

Respiratory problems are more frequent during the removal of a tracheal tube. The optimal time to withdraw the tube remains unclear. When the patient is fully awake, there is more protection, however it is associated with increased bleeding. Conversely, with a sedated patient, the airway can be obstructed and is not protected against aspiration. Respiratory complications associated with removal of the laryngeal mask airway have not been related to the anesthesia depth ${ }^{10}$.

In this study, it was removed the laryngeal mask airway or tracheal tube after the patients were awake to ensure adequate control of the airway. $\mathrm{SpO}_{2}$ values were higher in the LMA group upon removal of the device and after being admitted to the post-anesthesia care unit compared to the TT group. Respiratory events (wheezing, stridor, laryngospasm and bronchospasm) were similar between the two groups.

Previous studies have shown that the laryngeal mask airway can minimize laryngeal trauma during procedures in which the anesthesiologist and surgeon share the surgical field . It has been suggested that laryngeal mask airways protect both pediatric and adult airways against blood, secretions and debris during dental and otorhinolaryngological surgeries ${ }^{13}$, which can be confirmed by fiberoptic endoscopy ${ }^{14}$. In this study, when we removed the laryngeal mask airway, it can beobserved that the part of the mask that maintained contact with the larynx was bloody in some cases. This may have been caused by passage through the oral cavity.

During adenotonsillectomies, the tracheal tube or laryngeal mask airway may be compressed by the mouth opener. We opted to place the laryngeal mask airway inside of the retractor to avoid compression by the dental arch, and the mask remained in place using this method. However, the area in which the mask made contact with the airway was greater in distal regions. Surgical technique is fundamental when using disposable laryngeal mask airways for adenotonsillectomies. Sutures were not used in the tonsillar fossa, which is a procedure that, when necessary, requires a wider operative field and may pierce the cuff of the laryngeal mask airway. Opening the mouth with a surgical retractor is described as a trigger for laryngospasm. The risk of laryngospasm can be minimized with a deep plane of anesthesia and the use of opioids. 
One patient regurgitated gastric content via the laryngeal mask airway after mouth opener placement. The incidence of regurgitation when the laryngeal mask airway is correctly positioned is $0.1 \%$ and is associated with a superficial depth of anesthesia and high inspiratory pressure ${ }^{15}$. In the present study, placing the mouth opener may have stimulated the regurgitation.

Some reports show that when a laryngeal mask airway is used in adenotonsillectomies the surgeon cannot distinguish it from a tracheal tube after the mouth opener has been placed. This was not observed in our study because these previous reports used reinforced laryngeal mask airways and BoyleDavis mouth openers.

The use of laryngeal mask airways may impair surgical access, which may increase the operative time, increase the need for aspirating oral blood and decrease the amount of tonsil tissue removed ${ }^{16}$. In this study, although there was a need for proper positioning of the mouth opener, there were no sta- tistically significant differences in operative times. Conversely, the surgeon can move the tracheal tube in search of better visualization, resulting in extubation, selective or esophageal intubation and subglottic irritation with edema, which can increase the chances of respiratory complications ${ }^{17}$.

We conclude that the use of a laryngeal mask airway in adenotonsillectomies is possible. However, the occurrence of potentially serious complications such as hypoxemia and the need to exchange the laryngeal mask airway for a tracheal tube during the surgical procedure indicate that a tracheal tube should be preferentially used over a disposable laryngeal mask airway during adenotonsillectomies.

\section{ACKNOWLEDGEMENTS}

The authors would like to thank Dr. Mario José da Conceição and Professor Leo Lynce. 
5. Nascimento Jr P, Neves LBJ, Modolo NS et al. - Complicações respiratórias em crianças submetidas à anestesia geral. Rev Bras Anestesiol, 2000;50:345-349.

6. Adewale $L-$ Anatomy and assessment of the pediatric airway. Paediatr Anaesth, 2009;19(Suppl 1):1-8.

7. Webster AC, Morley-Forster PK, Dain S et al. - Anaesthesia for adenotonsillectomy: a comparison between tracheal intubation and the armoured laryngeal mask airway. Can J Anaesth, 1993;40:11711177.

8. Lim NL - The use of the laryngeal mask airway in post-tonsillectomy haemorrhage--a case report. Ann Acad Med Singapore, 2000;29:764765.

9. Boisson-Bertrand D - Modified laryngeal mask for adenotonsillectomy in children. Ann Fr Anesth Reanim, 1993;12:82-83.

10. Splinter WM, Reid CW - Removal of the laryngeal mask airway in children: deep anesthesia versus awake. J Clin Anesth, 1997;9:4-7.

11. Daum RE, O'Reilly BJ - The laryngeal mask airway in ENT surgery. J Laryngol Otol, 1992;106:28-30.

12. Sanchez Gomez S, Garcia Iriarte MT, Abrante Jimenez A et al. - Laryngeal mask anesthesia technique in adenoidectomy procedures with or without tonsillectomy. Acta Otorrinolaringol Esp, 1998;49:389396.

13. Aziz L, Bashir $\mathrm{K}$ - Comparison of armoured laryngeal mask airway with endotracheal tube for adenotonsillectomy. J Coll Physicians Surg Pak, 2006;16:685-688.

14. Yazbeck-Karam VG, Aouad MT, Baraka AS - Laryngeal mask airway for ventilation during diagnostic and interventional fibreoptic bronchoscopy in children. Paediatr Anaesth, 2003;13:691-694.

15. Ismail-Zade IA, Vanner RG - Regurgitation and aspiration of gastric contents in a child during general anaesthesia using the laryngeal mask airway. Paediatr Anaesth, 1996;6:325-328.

16. Hern JD, Jayaraj SM, Sidhu VS et al. - The laryngeal mask airway in tonsillectomy: the surgeon's perspective. Clin Otolaryngol Allied Sci, 1999;24:122-125.

17. Gravningsbraten R, Nicklasson B, Raeder J - Safety of laryngeal mask airway and short-stay practice in office-based adenotonsillectomy. Acta Anaesthesiol Scand, 2009;53:218-222.

\section{REFERENCES}

1. Kretz FJ, Reimann B, Stelzner $\mathrm{J}$ et al. - The laryngeal mask in pediatric adenotonsillectomy. A meta-analysis of medical studies. Anaesthesist, 2000;49:706-712.

2. Al-alami AA, Zestos MM, Baraka AS - Pediatric laryngospasm: prevention and treatment. Curr Opin Anaesthesiol, 2009;22:388-395.

3. Williams PJ, Bailey PM - Comparison of the reinforced laryngeal mask airway and tracheal intubation for adenotonsillectomy. Br J Anaesth, 1993;70:30-33.

4. Jefferson N, Riffat F, McGuinness $\mathrm{J}$ et al. - The laryngeal mask airway and otorhinolaryngology head and neck surgery. Laryngoscope, 2011;121:1620-1626. 